\title{
Modulation of Anxiety-Like Behavior and Morphine Dependence in CREB-Deficient Mice
}

\author{
Olga Valverde ${ }^{1,5}$, Theo Mantamadiotis ${ }^{2,4,5}$, María Torrecilla ${ }^{3}$, Luisa Ugedo ${ }^{3}$, Joseba Pineda ${ }^{3}$, Susanne \\ Bleckmann', Peter Gass ${ }^{2}$, Oliver Kretz ${ }^{2}$, Jennifer M Mitchell', Günther Schütz ${ }^{2}$ and Rafael Maldonado*, \\ 'Laboratori de Neurofarmacologia, Facultat de Ciènces de la Salut i de la Vida, Universitat Pompeu Fabra, Barcelona, Spain; ${ }^{2}$ Division Molecular \\ Biology of the Cell I, German Cancer Research Center, Heidelberg, Germany; ${ }^{3}$ Department of Pharmacology, Faculty of Medicine, University \\ of the Basque Country, Leioa, Bizkaia, Spain; ${ }^{4}$ Differentiation and Transcription Laboratory, Peter MacCallum Cancer Institute, \\ East Melbourne, Australia
}

\begin{abstract}
The transcription factor cAMP-responsive element binding protein (CREB) has been shown to regulate different physiological responses including drug addiction and emotional behavior. Molecular changes including adaptive modifications of the transcription factor CREB are produced during drug dependence in many regions of the brain, including the locus coeruleus (LC), but the molecular mechanisms involving CREB within these regions have remained controversial. To further investigate the involvement of CREB in emotional behavior, drug reward and opioid physical dependence, we used two independently generated CREB-deficient mice. We employed the Cre/loxP system to generate mice with a conditional CREB mutation restricted to the nervous system, where all CREB isoforms are lacking in the brain $\left(\mathrm{Creb} /{ }^{\mathrm{Nes} C r e}\right)$. A genetically defined cohort of the previously described hypomorphic Creb/ ${ }^{\alpha \Delta}$ mice, in which the two major transcriptionally active isoforms ( $\alpha$ and $\Delta$ ) are disrupted throughout the organism, were also used. First, we investigated the responses to stress of the CREB-deficient mice in several paradigms, and we found an increased anxiogenic-like response in the both Creb/ mutant mice in different behavioral models. We investigated the rewarding properties of drugs of abuse (cocaine and morphine) and natural reward (food) using the conditioned place-preference paradigm. No modification of motivational responses of morphine, cocaine, or food was observed in mutant mice. Finally, we evaluated opioid dependence by measuring the behavioral expression of morphine withdrawal and electrophysiological recordings of LC neurons. We showed an important attenuation of the behavioral expression of abstinence and a decrease in the hyperactivity of LC neurons in both Creb / mutant mice. Our results emphasize the selective role played by neuronal CREB in emotional-like behavior and the somatic expression morphine withdrawal, without participating in the rewarding properties induced by morphine and cocaine.

Neuropsychopharmacology (2004) 29, I I22-1 I33, advance online publication, 17 March 2004; doi: I 0.1038/sj.npp. I3004 I6
\end{abstract}

Keywords: emotional behavior; opiate addiction; conditioned place preference; CREB; knockout mice; locus coeruleus

\section{INTRODUCTION}

Within the central nervous system, cAMP-responsive element binding protein (CREB) activity is involved in many neuronal processes including neuronal survival (Lonze et al, 2002; Mantamadiotis et al, 2002), long-term memory (Bourtchuladze et al, 2002; Josselyn et al, 2002), molecular changes induced by antidepressants (Nibuya et al,

\footnotetext{
*Correspondence: Dr R Maldonado, Laboratori de Neurofarmacologia, Facultat de Ciènces de la Salut i de la Vida, Universitat Pompeu Fabra, C/ Doctor Aiguader, 80, Barcelona E-08003, Spain, Tel: + 3493-265- | 4-88; Fax: + 34-93-542-28-02,

E-mail: rafael.maldonado@upf.edu

${ }^{5}$ These authors contributed equally to this work

Received 19 September 2003; revised 09 January 2004; accepted 14 January 2004

Online publication: 21 January 2004 at http://www.acnp.org/citations/ Npp0 12 10403427/default.pdf
}

1996; Thome et al, 2000, Nestler et al, 2002), and drug dependence (Maldonado et al, 1996; Carlezon et al, 1998; Berke and Hyman, 2000; Nestler, 2001). In these cases, changes in CREB levels and in CRE-mediated transcription have been observed in several discrete brain areas (Thome et al, 2000; Nestler, 2001). In the case of opioids, the acute administration inhibits adenylyl cyclase activity, whereas chronic opioid treatment leads to a dramatic upregulation of the cAMP pathway at every major step of the cascade between receptor activation and physiological response (Nestler, 1997). This upregulation occurs in discrete brain areas including the locus coeruleus (LC) and the nucleus accumbens, providing a neuroanatomical link for opioid physical dependence and rewarding effects, respectively ( $\mathrm{Di}$ Chiara and North, 1992; Maldonado et al, 1992a, b; Koob and Le Moal, 1997). The upregulation of the cAMP pathway also seems to be involved in the addictive mechanisms of other drugs of abuse, such as cocaine (Carlezon et al, 1998; 
Nestler and Aghajanian, 1997). Transcription factors modulated by the CAMP pathway include the CREB and the cAMP-responsive element modulatory protein, CREM (Mayr and Montminy, 2001). The phosphorylation state of CREB was shown to decrease in the LC after acute morphine administration, whereas chronic morphine produces an increase in the phosphorylation and expression of CREB in this structure (Guitart et al, 1992; Nestler et al, 1993; LaneLadd et al, 1997). The nucleus accumbens plays a critical role in rewarding properties of different drugs of abuse and contributes, together with other limbic structures, in regulating emotional behavior (Nestler, 2001; Nestler et al, 1993; Koob et al, 1998).

It has been demonstrated that CREB is an important element involved in the onset of behavioral manifestations of opiate withdrawal, since the major signs of morphine abstinence were strongly attenuated in $\mathrm{Creb}^{\alpha \Delta}$ mutant mice, which lack the major transactivating CREB $\alpha$ and $\Delta$ isoforms (Maldonado et al, 1996). Other work utilizing antisense oligonucleotides has also implicated decreased CREB expression in the LC with attenuated withdrawal and electrophysiological responses (Lane-Ladd et al, 1997). On the other hand, local changes in CREB activity in the nucleus accumbens alters reactions to anxiogenic, aversive, and nociceptive stimuli (Barrot et al, 2002; Graves et al, 2002; Pandey et al, 2003; Pandey, 2003), whereas it has also been reported that the aversive properties of morphine are present in CREB mutant mice (Walters and Blendy, 2001).

To further investigate the role of CREB in emotional behavior and drug dependence, we used two independent Creb1 mutant mice allowing us to distinguish the role of global CREB deficiency and brain-specific CREB loss. On the one hand, we chose to perform these experiments on the previously described hypomorphic Creb1 ${ }^{\alpha \Delta}$ mice, in which the two major transcriptionally active isoforms ( $\alpha$ and $\Delta$ ) are disrupted throughout (Maldonado et al, 1996), which for this study, were backcrossed for seven generations into the C57BL/6 strain. To complement and further refine these analyses, and since complete ablation of CREB in mice results in perinatal death (Rudolph et al, 1998), we employed the Cre/loxP system to generate mice devoid of all CREB isoforms specifically in the nervous system $\left(\mathrm{Creb} 1^{\mathrm{NesCre}}\right.$ mice). This was achieved by using mice harboring loxP sites within the Crebl gene (Mantamadiotis et al, 2002) and a Cre-recombinase transgene under the control of the nestin promoter enhancer (Tronche et al, 1999). These brain-specific mutant mice lack all CREB isoforms in almost all nerve cells, and not just CREB $\alpha$ and $\Delta$ isoforms.

In this study, we show that $C r e b 1^{\text {NesCre }}$ mice exhibit elevated anxiety-like behavior and that naloxone-precipitated morphine withdrawal syndrome is attenuated in both $C r e b 1^{\alpha \Delta}$ and $C r e b 1^{\text {NesCre }}$ mice. We provide evidence linking the attenuated withdrawal response with a reduced firing rate of $L C$ neurons in these mice. In $C r e b 1^{\alpha \Delta}$ and $C r e b 1^{\text {NesCre }}$ mice, the withdrawal response was attenuated, both morphine and cocaine rewarding effects were not significantly perturbed in the conditioned placepreference paradigm, revealing a CREB participation in improving emotional states as well as a clear dissociation between opioid physical dependence and motivational responses.

\section{MATERIALS AND METHODS}

\section{$\mathrm{Creb1}^{\mathrm{NesCre}}$ Mice}

Mice harboring the CreblloxP allele (Mantamadiotis et al, 2002) were crossed with transgenic mice possessing a transgene for Cre recombinase under the control of the nestin promoter and enhancer (Tronche et al, 1999). Two successive crosses were necessary to obtain mutant mice homozygous for the CreblloxP allele and harboring one allele of the nestin Cre transgene, with the second cross being $\mathrm{WT} / \operatorname{lox} \mathrm{P}-$ nestinCre $\times \operatorname{loxP} /$ loxP mice. In this case, mutant mice were obtained at the expected Mendelian ratio of $25 \%$. Mice were bred in a genetic background comprising of a mix of 129SvOla and C57BL/6. Genotyping of mice with the Creb1loxP allele was performed using PCR primers as described previously (Mantamadiotis et al, 1998), while the nestinCre transgene was detected by tail DNA slot-blot analysis. Control animals in all experiments were Creb1 $1^{\text {loxP/loxP }}$ without the nestin transgene. Mice used in this study were between 9 and 14 weeks old.

\section{$\mathrm{Creb1}^{\alpha \Delta}$ Mice}

$C r e b 1^{\alpha \Delta}$ mutant mice were generated as described previously (Hummler et al, 1994). Mutant mice and the wildtype controls used in this study were in a more homogeneous $\mathrm{C} 57 \mathrm{BL} / 6$ genetic background achieved by successive backcrossing to C57BL/6 mice for seven generations. Mice used in this study were between 9 and 14 weeks old.

\section{Mouse Handling}

Animals were housed in a temperature-controlled environment $\left(21 \pm 1^{\circ} \mathrm{C}\right)$ with free access to food and water. Mice were allowed to become acclimatized to the experimental room and were handled during the week before initiating experiments. Behavioral tests and care of the animals were in accordance with standard ethical guidelines (NIH, 1985; European Communities Directives, 1986 86/609/EEC) and approved by a local ethical committee. All experiments were performed blind with respect to genotype.

\section{Immunohistochemical Analysis}

Mice were perfused with cold 4\% PFA, brains were dissected and postfixed for $16 \mathrm{~h}$ in PFA at $4{ }^{\circ} \mathrm{C}$ prior to embedding in $2 \%$ agarose in phosphate-buffered saline (PBS) or paraffin. Agarose-embedded brains were sectioned using a Vibratome cutter at a thickness of $50 \mu \mathrm{m}$, while paraffin sections were sectioned on a microtome at a thickness of $7 \mu \mathrm{m}$. Rabbit antibodies directed against CREB (recognizing an epitope in the N-terminal half, residues 136-150) or CREM antibodies were used at dilutions of between 1:3000 and 1:10000 as described previously (Blendy et al, 1996a). For dual antigen detection, paraffin sections were incubated with a mixture of rabbit anti-CREB (1:3000) and mouse anti-tyrosine hydroxylase (TH) (1:400; Chemicon) antibodies. Sections were then incubated with a biotinylated goat anti-rabbit antibody (Vectastain) followed by HRPavidin-biotin substrate (Vectastain). The reaction was visualized by treating for 3 min with $0.05 \%$ 3, $3^{\prime}$-diaminobenzidine 
tetrahydrochloride solution in PBS containing $0.05 \% \mathrm{H}_{2} \mathrm{O}_{2}$. After rinsing and blocking, sections were subsequently incubated with a goat anti-mouse AP-conjugated antibody (Chemicon), appropriately washed and the second precipitate developed with Vector Blue chromagen (Vector Laboratories). Finally, rinsed sections were mounted and coverslipped with an aqueous mounting medium (Sigma).

\section{Behavioral Experiments}

Locomotor activity boxes. Mice were placed individually in locomotor activity boxes consisting of a plastic rectangular area $(255 \mathrm{~cm} \times 205 \mathrm{~cm})$ with two crossed photocells, isolated in a soundproof furniture and in almost complete darkness $(<5 \mathrm{~lx})$. The number of activity counts was evaluated during $15 \mathrm{~min}$ on the testing days starting at 1400 .

Open field. Each animal was placed in the open-field apparatus consisting of a rectangular area $(70 \mathrm{~cm}$ wide $\times 90$ $\mathrm{cm}$ long $\times 60 \mathrm{~cm}$ high) under bright illumination $(500 \mathrm{~lx})$. In all, 63 squares $(10 \mathrm{~cm} \times 10 \mathrm{~cm})$ were drawn with black lines on the white floor of the apparatus. The parameters measured during the observation session of $5 \mathrm{~min}$ were: the latency of crossing the first two squares from the central square where the mouse was initially placed; the number of squares crossed in the peripheral and central area of the field; entries into the central area; rearings; grooming bouts; defecation boli left in the field; and urination events.

Elevated zero maze. The zero maze (diameter, $46 \mathrm{~cm}$; runway width, $5.5 \mathrm{~cm}$ ) consisted of a Plexiglass apparatus with two open and two wall-enclosed sectors of equal size (König et al, 1996). The maze was elevated $50 \mathrm{~cm}$ above the ground and illuminated from the top $(100 \mathrm{~lx})$. Animals were placed on one open sector in front of an enclosed sector. The position of the mouse was recorded by a video camera, and the time spent in each arm was measured for $5 \mathrm{~min}$ by a program provided with the Videotrack II, 2.12 version computer (ViewPoint, Lyon, France). Time in a new sector was measured as soon as the animal entered with four paws. The general activity was assessed by counting all entries with at least two paws into a new sector. Mice were exposed to the test at 1400 .

Elevated plus maze. The elevated plus maze consisted of black Plexiglass apparatus with four arms $(16 \mathrm{~cm}$ long and $5 \mathrm{~cm}$ wide) set in a cross from a neutral central square $(5 \mathrm{~cm} \times 5 \mathrm{~cm})$. Two opposing arms were delimited by vertical walls (closed arms), while the two other opposing arms had unprotected edges (open arms). The maze was elevated $30 \mathrm{~cm}$ above the ground and placed in indirect light $(100 \mathrm{~lx})$. At the beginning of the $5 \mathrm{~min}$ observation session, each mouse was placed in the central neutral zone, facing one of the open arms. The total number of visits into the closed arms, open arms, and the cumulative times spent in the open arms and closed arms were observed via a video camera system (ViewPoint, Lyon, France). An arm visit was recorded when the mouse moved all four paws into the arm.

Black and white box. The box consists of a small $(15 \mathrm{~cm} \times 20 \mathrm{~cm} \times 25 \mathrm{~cm})$ dimly lit $(5 \mathrm{~lx})$ compartment, with black walls and a black floor, connected by a $4 \mathrm{~cm}$ long tunnel leading to a larger compartment $(30 \mathrm{~cm} \times$ $20 \mathrm{~cm} \times 25 \mathrm{~cm}$ ) with white walls and white floor, intensely lit $(500 \mathrm{~lx})$. Lines were drawn on the floor of both compartments permitting the measurement of locomotor activity by counting the number of squares crossed. Each animal was placed in the dark compartment facing the tunnel at the beginning of the observation session. Latency to go for the first time to the lit compartment (s), time spent in and number of entries into each compartment, as well as the number of squares crossing in each compartment were recorded for $5 \mathrm{~min}$.

Conditioned place preference. Conditioned place-preference tests were performed as described previously (Maldonado et al, 1997). One compartment of the placepreference apparatus is randomly chosen for drug association and the other to saline. No initial preference for any compartment was revealed in all animal groups. Care was taken to ensure that treatments were counterbalanced as closely as possible between compartments. The placepreference conditioning schedule consisted of three phases: (1) Preconditioning phase, during which mice were placed in the middle of the neutral area and their location was recorded for $18 \mathrm{~min}$. (2) Conditioning phase, during which mice were treated for 6 consecutive days with alternate injection of drug (morphine, $4 \mathrm{mg} / \mathrm{kg}$, s.c.) (days 1, 3, and 5) or saline (days 2, 4, and 6). Control animals received saline everyday. During this phase, $\operatorname{Creb} 1^{\alpha \Delta}$ mutant mice received morphine $(4 \mathrm{mg} / \mathrm{kg}$, s.c.; cocaine, $20 \mathrm{mg} / \mathrm{kg}$, i.p. or food pellets). (3) Testing phase, which was conducted $24 \mathrm{~h}$ after the final conditioning session exactly as the preconditioning phase; that is, free access to each compartment for $18 \mathrm{~min}$. Results are presented as the total time spent in the drugpaired compartment $v s$ time spent in the vehicle-paired compartment during testing session.

Morphine withdrawal syndrome. Opioid dependence was induced by repeated morphine injection. The morphine dose (i.p.) was progressively increased from 20 to $100 \mathrm{mg} / \mathrm{kg}$ over a period of 5 days. The first and second numbers inside the parenthesis represent the doses of morphine $(\mathrm{mg} / \mathrm{kg})$ injected at 0900 and 1900, respectively: 1 st day $(20,20) ; 2$ nd day $(40,40), 3$ rd day $(60,60)$, 4 th day $(80,80)$, 5 th day $(100$, $100)$, and 6 th day $(100 \mathrm{mg} / \mathrm{kg}$, only in the morning). Morphine withdrawal syndrome was precipitated by naloxone injection $(1 \mathrm{mg} / \mathrm{kg}$, s.c.) $2 \mathrm{~h}$ after the last morphine administration. Mouse behavior was observed immediately after naloxone administration, as reported previously (Maldonado et al, 1996). The following signs were measured for $30 \mathrm{~min}$ : jumping, wet dog shakes, paw tremor, teeth chattering, body tremor, ptosis, piloerection, and sniffing. A global withdrawal score was also calculated for each animal by giving to each individual signs a specific weight as reported previously (Maldonado et al, 1992a, b).

\section{Electrophysiological Recordings from LC Neurons}

For electrophysiological studies, opioid dependence was induced in mice by using the protocol described above. Mice were anesthetized with chloral hydrate $(400 \mathrm{mg} /$ $\mathrm{kg}$, i.p.) and decapitated $1-4 \mathrm{~h}$ after the last morphine 
injection. Opioid withdrawal was precipitated in vitro on the brain slice preparations by allowing morphine to wash out (spontaneous withdrawal) (see below). Midpontine slices were prepared as described previously (Lane-Ladd et al, 1997). Coronal slices of $400 \mu \mathrm{m}$ thickness including the LC were prepared with a vibrating knife microtome (Vibroslice, BHC), transferred onto the stage of a modified gas-liquid interface chamber at $32-33^{\circ} \mathrm{C}$, and perfused at a constant flow rate of $1 \mathrm{ml} / \mathrm{min}$ with artificial cerebrospinal fluid (CSF). CSF was composed of (in $\mathrm{mM}$ ): $126 \mathrm{NaCl}, 3 \mathrm{KCl}$, $1.25 \mathrm{NaH}_{2} \mathrm{PO}_{4}, 22 \mathrm{NaHCO}_{3}, 2 \mathrm{CaCl}_{2}, 2 \mathrm{MgSO}_{4}$, and 10 glucose, saturated with $95 \% \mathrm{O}_{2} / 5 \% \mathrm{CO}_{2}$ for a final $\mathrm{pH}$ of 7.34. Extracellular potentials were recorded by blunt-tipped glass microelectrodes filled with a $50 \mathrm{mM} \mathrm{NaCl}$ solution (2$5 \mathrm{M} \Omega$ ), and then monitored through a high-input impedance amplifier on an oscilloscope and by an audio analyzer. Single-unit spikes were discriminated and counted by a custom-made computer program creating chart recordings in consecutive $10 \mathrm{~s}$ intervals. The $\mathrm{LC}$ was visually identified as a dark oval area in the upper pons on the lateral borders of the central gray and the fourth ventricle, just anterior to the genu of the facial nerve. LC cells displayed spontaneous firing activity at regular rhythms and long-lasting positive-negative waveforms. Consecutive cells were sampled for $80-90 \mathrm{~min}$ by multiple electrode tracts randomly positioned within the LC during opiate withdrawal. We started recording $90 \mathrm{~min}$ after preparation of the slice to allow morphine to wash out (Kogan et al, 1992). In some experiments, the firing rate of LC neurons was also recorded after bath application of naloxone $(1 \mu \mathrm{m}$ for $10 \mathrm{~min}$ ), to test the presence of residual morphine in the slice. In these cases, naloxone was dissolved in the CSF and applied to the tissue by changing the perfusion medium by means of a three-way stopcock valve.

The firing rate value in each cell was obtained by averaging the values recorded for at least $2 \mathrm{~min}$, so that the stability of the discharge was ensured. The mean firing rate of all the cells sampled in each slice was considered as an individual point for statistical analysis.

\section{Statistical Analysis}

All values are given as mean \pm SEM. Statistical comparisons for behavioral studies were analyzed by using a two-way analysis of variance (ANOVA). The factors of variation were genotype (between subjects) and treatment (between subjects). Following corresponding one-way ANOVA, a post hoc analysis was performed by using the NewmanKeuls test. For the conditioned place-preference studies, the comparison between the time spent in the drug-paired compartment and the vehicle-paired compartment was made by using a Student's $t$-test. In all the experiments, the level of significance was $p<0.05$.

\section{RESULTS}

\section{Characterization of Mice Lacking CREB in the Brain}

Mice homozygous for $\mathrm{Crebl}^{\text {loxP }}\left(\mathrm{Crebl}^{\text {loxP/loxP}}\right)$ were completely normal and showed the expected CREB protein expression profile (Figure 1a, c, and e). The modified allele however, is sensitive to Cre recombinase, which binds to the

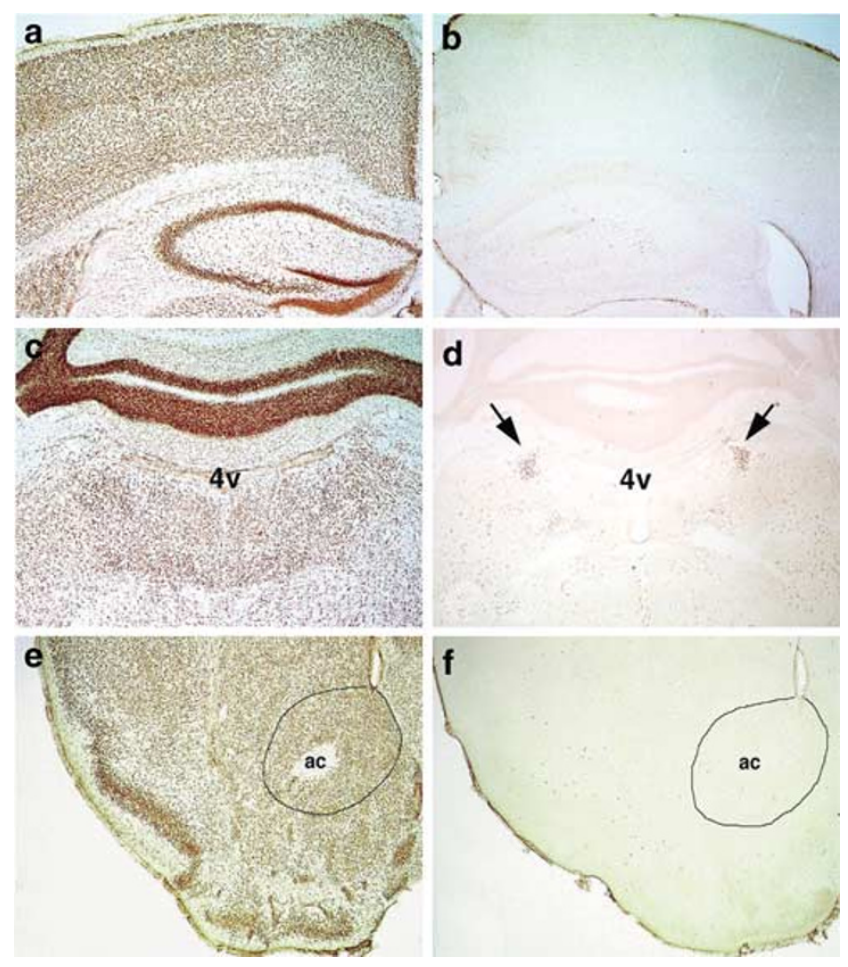

Figure I Loss of CREB protein in nervous system of Creb/ ${ }^{\text {NesCre }}$ mice. Agarose-embedded sections $(50 \mu \mathrm{m})$ were used to immunohistochemically analyze CREB protein distribution in control (Crebl loxP/loxP $)(a, c$, and e) and $\mathrm{Creb} /{ }^{\text {NesCre }}(\mathrm{b}, \mathrm{d}$, and $\mathrm{f})$ mice. CREB-positive neurons in the region encompassing the LC are indicated by arrows (d), while the region harboring the nucleus accumbens is also marked ( $e$ and $f)$. ( $a, b, e$, and $f$ ) $\times 20,50 \mu \mathrm{m}$ hippocampal section; (c and $\mathrm{d}$ ) $\times 20,50 \mu \mathrm{m}$ section including the LC.

loxP sites and excises the intervening DNA sequence. Mice harboring the $C r e b 1^{\text {loxP }}$ allele were crossed with transgenic mice possessing a transgene for the Cre recombinase under the control of the nestin promoter and enhancer (Tronche et al, 1999), directing Cre recombinase expression to the developing nervous system. Resulting newborn NestinCre Creb1 $1^{\text {loxP/loxP }}$ mice $\left(\mathrm{Creb}^{\mathrm{NesCre}}\right)$ were normal but by the second week showed a significant reduction in body size. Growth curves indicated that on average, Creb1 $1^{\text {NesCre }}$ mice nominally reached $70-80 \%$ of control mouse body weight. The reduction was not sex-specific, as both females and males showed similar reduced growth. Body weight reduction was not associated with visible physical malformations, such as the runting phenotype observed in $\mathrm{Gr}^{\text {Nescre }}$ mice (Tronche et al, 1999). There was also no apparent decline of robustness in movement nor life expectancy. The growth defect appears to result from an attenuated GH and IGF-I levels (TM unpublished). There is no evidence that the GH deficiency contributes significantly to the altered locomotor activity or behavior in the Creb $1^{\text {NesCre }}$ mice used in this study (see Discussion and Kinney et al, 2001).

\section{Immunohistochemical Analysis of CREB in Brain}

Creb $1^{\text {NesCre }}$ mice lacked CREB immunoreactivity in almost all neurons and glia, probing with either of the three antibodies recognizing CREB epitopes from the N-terminal 
half to the C-terminal end, indicating that no CREB protein, including truncated forms, were present (Figure $1 \mathrm{~b}, \mathrm{~d}$, and f). CREB recombination was specific to neurons and glia, as the anterior pituitary which is derived from the non-neural oral ectoderm showed no change in CREB expression (Mantamadiotis et al, 2002). Although Creb1 recombination was restricted to neural cells, some scattered neurons showed normal levels of CREB protein expression. Notably, CREB immunoreactivity was present in neurons of the LC (Figure 1d). By double-labeling immunocytochemistry, we determined that almost all TH-positive neurons in the mutant LC were also CREB positive (Figure 2a), comparable to the wild-type LC (Figure $2 \mathrm{~b}$ ). Since TH serves as a marker for the noradrenergic cells of the LC, we conclude that in the LC of $\mathrm{Creb}{ }^{\text {NesCre }}$ mice CREB expression is maintained. Some scattered cells identified as glia and neurons retained CREB immunoreactivity in other brain regions such as the hypothalamus, possibly reflecting small differences in nestin-driven Cre recombinase expression during neural development in particular brain regions. Small oval-shaped, positively staining nuclei, identified morphologically as glia, were also apparent throughout the brain. Compared to control mice the highly related CREM protein was

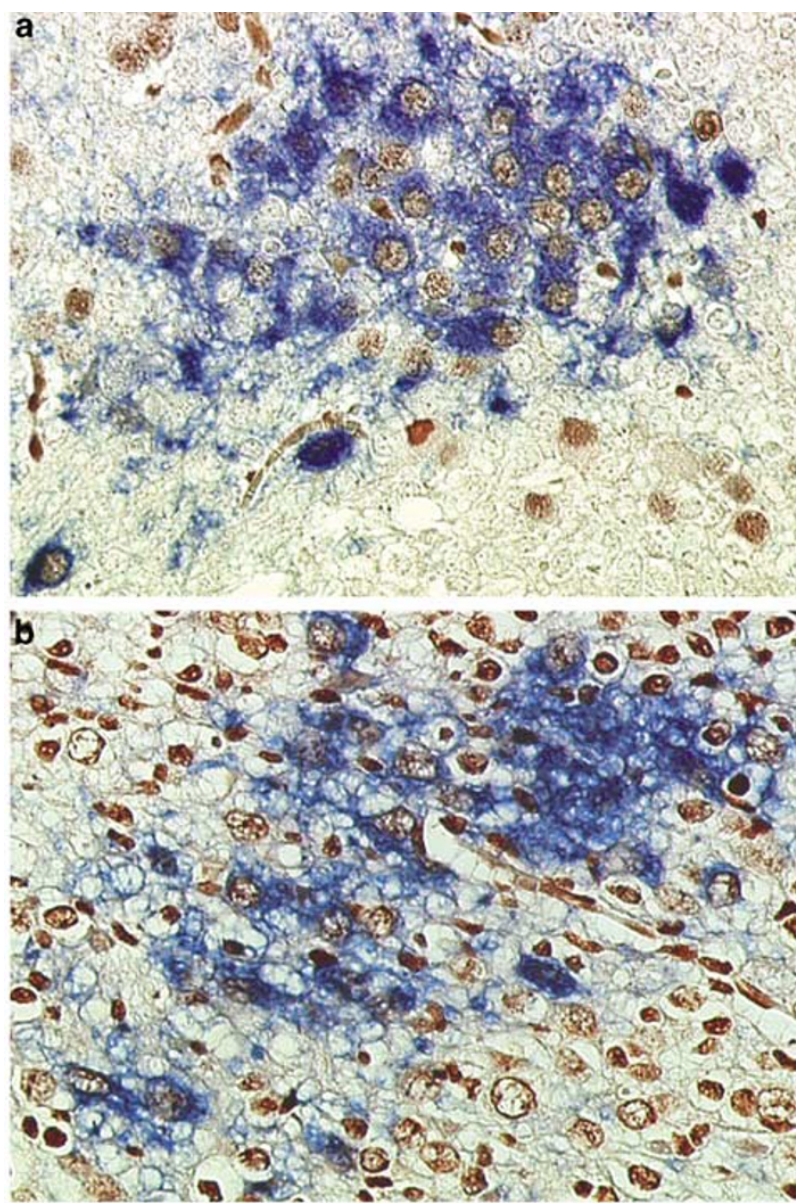

Figure 2 CREB is present in Creb/ NesCre mutant LC cells. Paraffin sections $(7 \mu \mathrm{m})$ from Creb/ ${ }^{\text {NesCre }}$ (a) and control Creb/ loxP/loxP $(b)$ mice, encompassing the LC, were immunostained sequentially with anti-CREB and anti-TH antibodies. TH signal is blue, while CREB-positive nuclei appear brown. Note the grainy appearance of CREB-positive nuclei in neurons and darker CREB-positive glial nuclei. upregulated in all cells devoid of CREB (data not shown), as previously observed in other Creb1 mutant mice (Rudolph et al, 1998; Hummler et al, 1994; Blendy et al, 1996b). This upregulation of CREM protein appears necessary for neuronal survival in CREB-deficient neurons (Mantamadiotis et al, 2002).

\section{Spontaneous Locomotor Activity in CREB-Deficient Mice}

First, spontaneous locomotor activity was evaluated in Creb $1^{\alpha \Delta}$ mice and control littermates ( $n=24-25$ per group). One-way ANOVA indicated a significant effect of the mutation $(p<0.05)$. Post hoc analysis showed that CREB deficiency elicited a significant decrease in spontaneous locomotor activity $(p<0.01)$ compared with wild-type mice. (Figure 3a). Unlike $C r e b 1^{\alpha \Delta}$ mice, $C r e b 1^{\text {NesCre }}$ mice did not display a significant decrease in locomotor activity compared with the control group (Figure 3a). However, when movements were dissected into small horizontal movements

a

Locomotor Activity

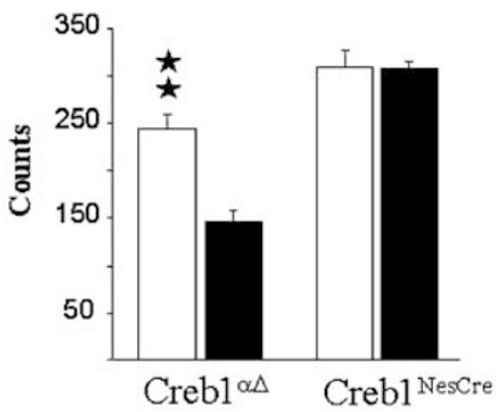

b Open Field in Creb1 ${ }^{\text {NesCre }}$
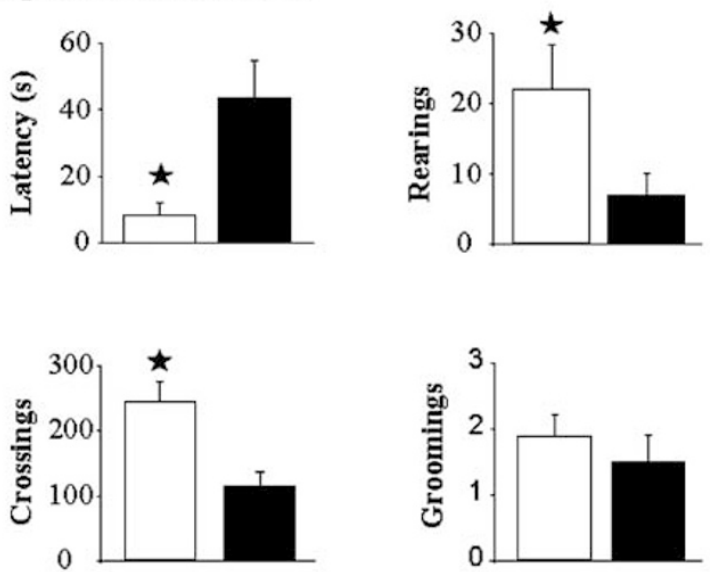

Figure 3 Spontaneous locomotor activity and anxiety-like behavior on the open-field test in CREB-deficient mice. (a) Locomotor activity was evaluated in the locomotor activity boxes during $15 \mathrm{~min}$. Creb/ ${ }^{\alpha \Delta}$ mice $(n=24-25)$. Mutant mice (black squares) displayed a hypolocomotor responses compared with the wild-type animals (white squares). Creb/ ${ }^{\text {NesCre }}$ mice $(n=24-25)$ showed no changes in locomotor behavior when comparing mutant (black squares) and wild-type (white squares) mice. (b) Results of open-field analysis in Creb/ NesCre mice $(n=\mid 4$, black squares) and control Creb/lox/lox littermates $(n=14$, white squares) are shown. One $5 \mathrm{~min}$ observation period is shown. Data are expressed as mean \pm SEM. One black star, $p<0.05$; two black stars, $p<0.0$ I. 
without rearing and vertical rearing activity only, we saw that rearing behavior was more obviously attenuated compared with small movements in $\mathrm{Creb}_{1}{ }^{\text {NesCre }}$ mice compared with controls, indicating decreased exploratory behavior (data not shown).

\section{Increased Anxiety in CREB-Deficient Mice}

We chose to assess the emotional-like behavior in $\mathrm{Creb} 1^{\text {NesCre }}$ where there is brain-specific CREB inactivation. Some tests were also carried out on the hypomorphic $\mathrm{Creb} 1^{\alpha \Delta}$ mice to compare the brain-specific and hypomorph mutants. Under stressfull situation, in the open-field test, large space and a high illumination $(500 \mathrm{~lx})$, a reduction in the locomotor activity was observed in $\mathrm{Crebl}^{\text {NesCre }}$ mice compared with the control group ( $n=12$ per group) (Figure 3b). This attenuation in the locomotion was observed in both horizontal (number of squares crossings) and vertical (number of rearings) activity $(p<0.05$ for all the cases). Furthermore, an increase in the latency of the first movement from the middle of the field was also observed in the mutant mice $(p<0.05)$, suggesting an anxiogenic-like response in this group of animals (Figure $3 \mathrm{~b}$ ). No differences in groomings, urination and defecation boli deposition were seen.

$\mathrm{Creb}^{\alpha \Delta}$ mice ( $n=24-25$ per group) were exposed to the elevated zero maze in order to evaluate their anxiety-like state (Figure 4a). Two different parameters were evaluated: the percentage of time spent in the open sector and the total number of sector visits. For the time spent in the open sector, one-way ANOVA indicated a significant effect $(p<0.001)$. Post hoc analysis showed a reduced percentage of the time spent by mutant mice in the open sector $(p<0.01)$, revealing a higher anxiety level in these mice. One-way ANOVA for the total number of visits indicated an effect of the mutation $(p<0.001)$. Post hoc analysis indicated that mutant animals exhibited a decrease in this parameter, indicative of the global locomotor activity $(p<0.01)$. Crebl $1^{\text {NesCre }}$ mice $(n=12$ per group) exhibited similar elevated zero maze behavior to $\mathrm{Creb}^{\alpha \Delta}$ mice with mutant animals spending less time in the open region, although the genotype effect was not statistically significant. However, the number of entries into the open compartment was significantly reduced (Figure $4 \mathrm{a}$ ), suggesting that under stressful conditions, CREB-deficient mice display a hypolocomotion. As Creb $1^{\text {NesCre }}$ mice are devoid of all CREB isoforms in the brain, we chose to extend the repertoire of tests to further define the effect of CREB loss on emotional behavior in these mice. Elevated plus maze activity reflected the zero maze observations with $C r e b 1^{\text {NesCre }}$ mice $(n=12$ per group) with fewer visits into the open arms when compared with the control group $(p<0.05)$, as well as less time spent in the open arms (Figure $4 \mathrm{~b}$ ). Finally and in a similar line with the previous experiments (elevated zero and plus maze), exposure to the black and white box demonstrated that $\mathrm{Creb}^{\mathrm{Nes} C r e}$ mice once again elicited higher anxiety-like responses than the wild-type group. Thus, the mutant mice exhibited an increased latency in visiting the white compartment for the first time $(p<0.05)$, less time spent into the light compartment $(p<0.05)$, and fewer entries into this compartment $(p<0.05)$ (Figure 5). a Elevated Zero-Maze
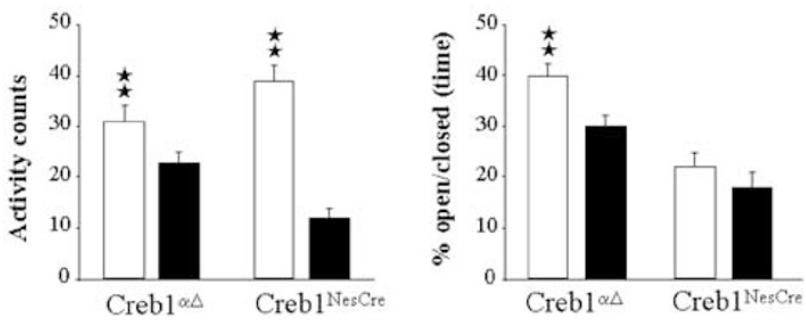

b

Elevated Plus Maze in Crebl ${ }^{\text {NesCre }}$
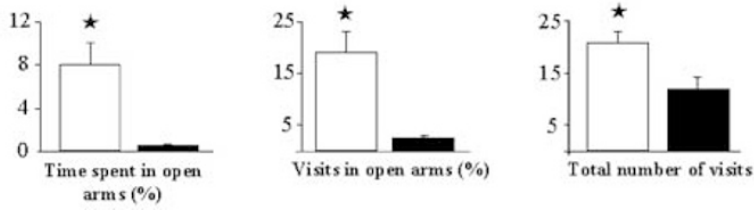

Figure 4 Increased anxiety-like behavior on the elevated zero and plus maze in CREB-deficient mice. Animals were analyzed for 5 min each. (a) On the elevated zero maze, both Creb/ ${ }^{\text {NesCre }}$ mice ( $n=14$, black squares) and Creb $1^{\alpha \Delta}$ mice $(n=24$, black squares) displayed more anxiety-like behaviors compared with Creb/lox/lox littermates $(n=14$, white squares) and wildtype littermates ( $n=24$, white squares), respectively, as measured by the $\%$ ratio of time spent in the open/closed arms and lower activity counts. The genotype effect for the \% ratio of time spent in the open/closed arms for Creb / NesCre mice was not statistically significant, but the activity counts measuring the number of visits into the open compartment was significantly shorter. Creb/ ${ }^{\alpha \Delta}$ mice showed significant reduction in both time spent and number of entries into the open compartment. (b) On the elevated plus maze, Creb/ $/^{\text {NesCre }}$ mice were analyzed for 5 min each. Creb/NesCre mice ( $n=14$, black squares) performed fewer visits into the arms of the maze and were especially reluctant to visit the open arms, and spent less time in

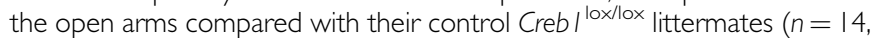
white squares). Data are expressed as mean \pm SEM. One black star, $p<0.05$; two black stars, $p<0.01$.
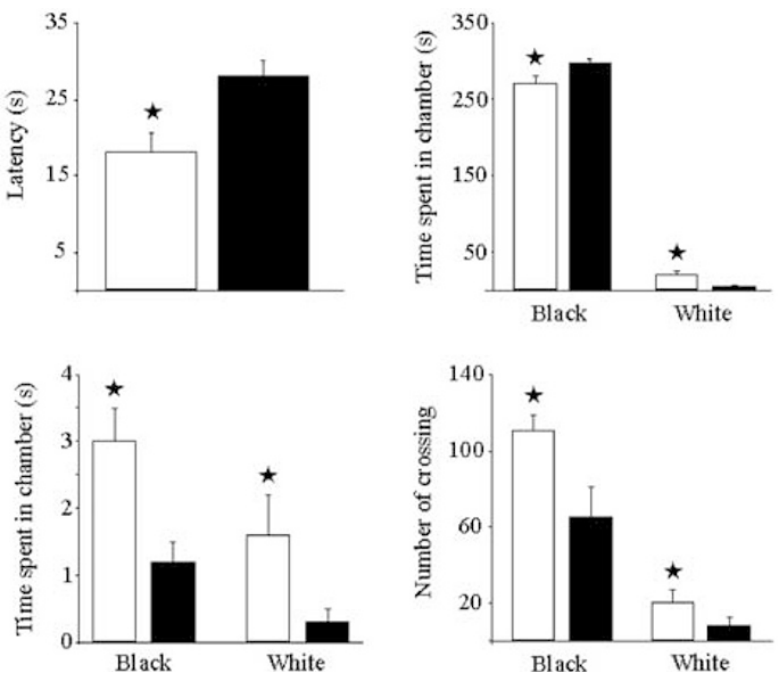

Figure 5 Increased anxiety-like behavior in CREB-deficient mice in the black and white box. Creb/ NesCre mice were analyzed for 5 min each. Creb/ Nescre mice ( $n=14$, black squares) displayed more anxiety-like responses than the control group ( $n=14$, white squares), as the mutants exhibited an increased latency in visiting the white compartment and less time spent in and fewer entries into the white compartment. Data are expressed as mean \pm SEM. One black star, $p<0.05$. 
All the results obtained in the specific behavioral models to evaluate the basal emotional-like behavior in mice are consistent with the previous data observed in the open-field test, demonstrating a heightened anxiety-like behavior in Creb $1^{\text {NesCre }}$ mice.

\section{Conditioned Place Preference in $\mathrm{Creb1}^{\mathrm{Nes} C r e}$ and $\mathrm{Creb1}{ }^{\alpha \Delta}$ Mice}

The rewarding properties induced by morphine in the conditioned place paradigm were investigated in $\mathrm{Creb} 1^{\mathrm{Nes} C r e}$ and $C r e b 1^{\alpha \Delta}$ mice ( $n=8-10$ per group) (Figures 6 and 7$)$. In addition, the rewarding properties of cocaine and food were also evaluated in $\operatorname{Creb}^{\alpha \Delta}$ mice ( $n=10-12$ per group) by using the same procedure. In the case of $\operatorname{Creb}^{\alpha \Delta}$ mice, animals spent more time in the drug-associated compartment for the three stimuli evaluated morphine administration $(p<0.05)$, cocaine administration $(p<0.01)$, and food $(p<0.01)$. No differences in the responses elicited in the conditioned place preference were observed between genotypes (Figure 6). The rewarding effects of morphine were also investigated in the $C r e b 1^{\text {NesCre }}$ mice. Again, all the animals exhibited a place preference for the drug-paired compartment $(p<0.01)$, but not differences were observed between wild-type and mutant mice (Figure 7).

\section{Morphine Withdrawal Syndrome in $\mathrm{Creb1}^{\mathrm{NesCre}}$ and Creb $^{\alpha \Delta}$ Mice}

We chose to study morphine-associated behaviors in the nervous system-specific CREB-deficient $\mathrm{Creb1} 1^{\mathrm{NesCre}}$ mice, together with the previously described hypomorphic $C r e b 1^{\alpha \Delta}$ mice. First, expression of somatic signs of naloxone-precipitated morphine withdrawal was evaluated in Creb1 mutant mice. Both $C r e b 1^{\text {NesCre }}$ mice and $C r e b 1^{\alpha \Delta}$ mice exhibited comparable attenuated withdrawal-associated behaviors, indicating that neuronal CREB plays a role in morphine withdrawal (Figure 8).

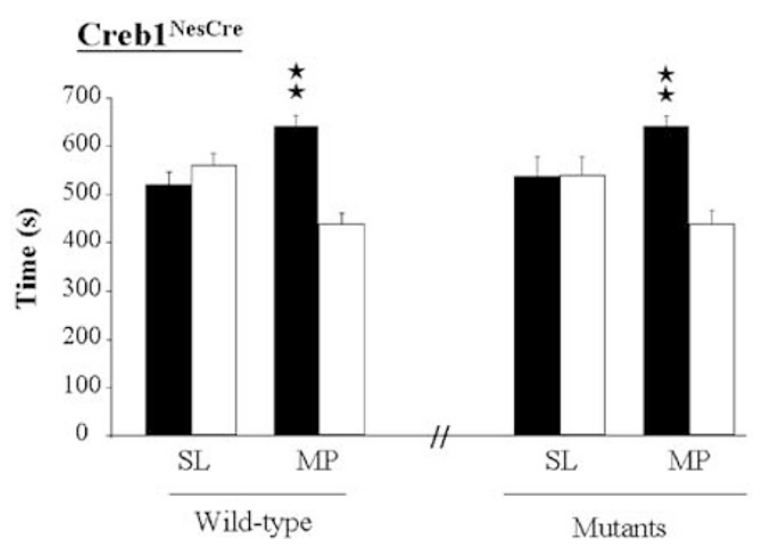

Figure 6 Rewarding effects of morphine ( $4 \mathrm{mg} / \mathrm{kg}$, s.c.), cocaine $(20 \mathrm{mg} /$ $\mathrm{kg}$, i.p.), and food evaluated in the conditioned place-preference paradigm in Creb $1^{\alpha \Delta}$ mice. Data are expressed as the total time spent in the drugpaired compartment vs the total time spent in vehicle-paired compartment for each drug evaluated. SL — saline treatment, MP — morphine treatment. (a) Represents results obtained in wild-type mice and (b) represents results obtained in mutant mice. Data are expressed as mean \pm SEM ( $n=8$ to I0). One black star, $p<0.05$; two black stars, $p<0.0$ I (Student's $t$-test).
Creb $1^{\text {NesCre }}$ mice exhibited significant attenuation of the following signs compared with control animals $(n=13-14$ per group): piloerection $(p<0.05)$, teeth chattering $(p<0.05)$, and paw tremor $(p<0.01)$, but no significant differences in jumping, ptosis, and body tremor. The number of wet dog shakes, however, was significantly increased $(p<0.05)$ in $C r e b 1^{\text {NesCre }}$ mice. Creb1 ${ }^{\alpha \Delta}$ mice exhibited almost identical attenuated withdrawal responses to those described previously (Maldonado et al, 1996). Comparisons of wild-type and mutant groups $(n=11-12$ per group) receiving chronic morphine treatment revealed a significant decrease in mutant mice in the expression of teeth chattering $(p<0.05)$, wet dog shakes $(p<0.05)$, paw tremor $(p<0.01)$, sniffing $(p<0.001)$, body tremor $(p<0.001)$, and piloerection $(p<0.05)$, but no significant differences in jumping (data not shown). The global withdrawal scores, determined for the mutant mice compared with controls, show that both $C r e b 1^{\text {NesCre }}$ and $C r e b 1^{\alpha \Delta}$ mice exhibited significantly attenuated responses $(p<0.05$ respectively) (Figure 8$)$.

\section{Withdrawal-Induced Hyperactivity of LC Neurons in Morphine-Dependent $\mathrm{Creb}^{\mathrm{NesCre}}$ and $\mathrm{Creb} 1^{\alpha \Delta}$ Mice}

An elevated activity of LC neurons has been postulated to contribute to the expression of opiate withdrawal in morphine-dependent rats (Kogan et al, 1992). To examine whether CREB plays a role in this withdrawal-induced hyperactivity, single-unit extracellular recordings of LC

\section{a Wild-type Creb1 ${ }^{\alpha \Lambda}$}

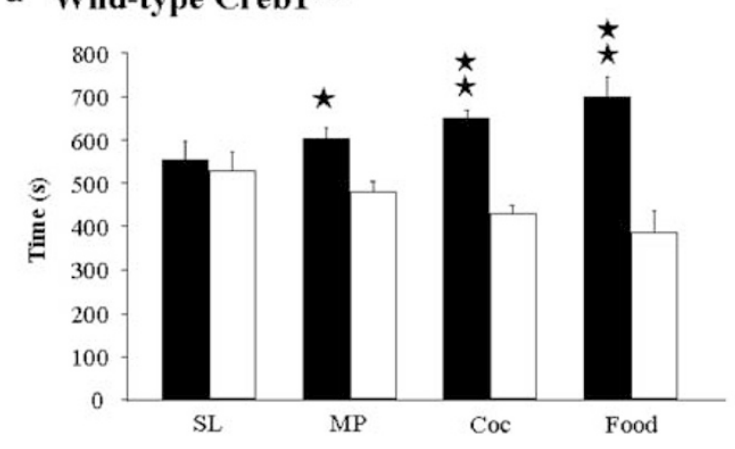

b Mutant Creb1 ${ }^{\alpha \Lambda}$

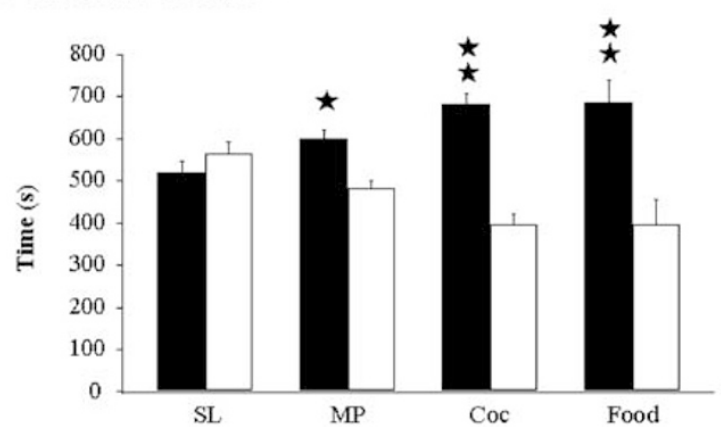

Figure 7 Rewarding effects of morphine ( $4 \mathrm{mg} / \mathrm{kg}$, s.c.) evaluated in the conditioned place-preference paradigm in Creb/ NesCre mice. Data are expressed as the total time spent in the drug-paired compartment vs the total time spent in vehicle-paired compartment for each drug evaluated. $\mathrm{SL}$ - saline treatment, MP - morphine treatment. Data are expressed as mean $\pm \operatorname{SEM}(n=8-10)$. Two black stars, $p<0.0$ I (Student's $t$-test). 

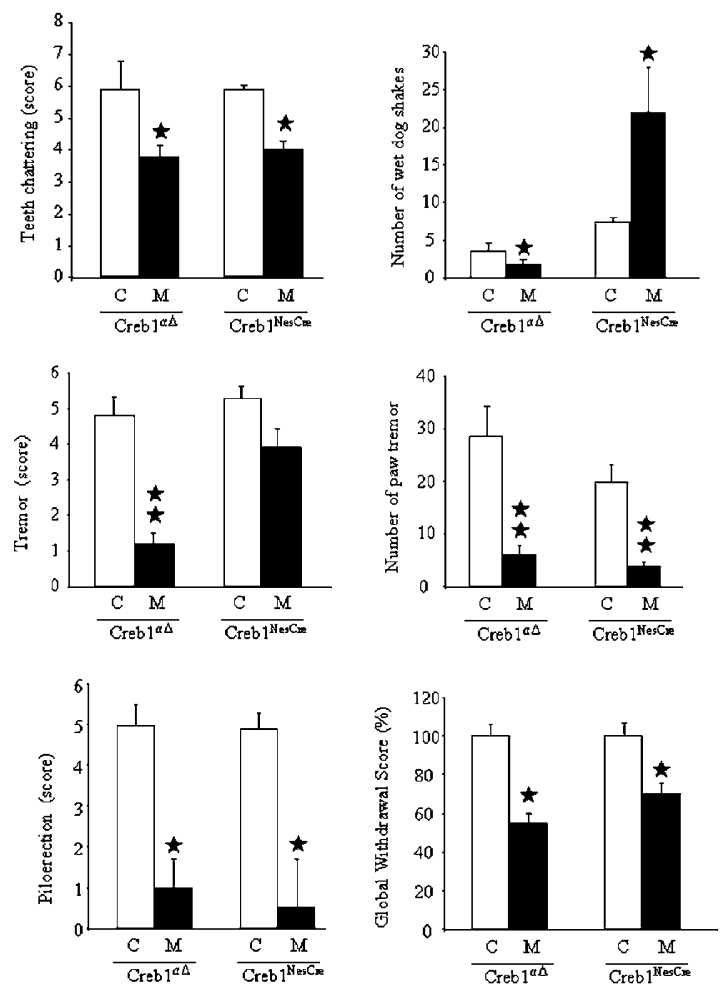

Figure 8 Manifestation of morphine withdrawal in CREB-deficient mice. Attenuation of morphine withdrawal syndrome in Creb/ mutant mice. Morphine withdrawal syndrome precipitated by naloxone (I mg/kg, s.c.) in $\mathrm{Creb} /{ }^{\mathrm{Nes} C r e}$ mice and $\left.\mathrm{Creb}\right|^{\alpha \Delta}$ mice. White columns represents wild-type animals (C) and black columns represent mutant mice (M). The withdrawal observation period was $30 \mathrm{~min}$. Experiments were performed on two cohorts of mice. Data are expressed as mean $\pm \operatorname{SEM}(n=||-\mid 2)$. A global withdrawal score was calculated by giving a range of possible scores from 0 to I 00 for each animal taking into account all the individual behavioral signs. One black star, $p<0.05$; two black stars, $p<0.01$ vs wild-type group receiving the same treatment (Newman-Keuls test).

neurons were obtained in brain slices from wild-type, $\mathrm{Creb} 1^{\mathrm{NesCre}}$ - and $\mathrm{Creb}_{1}{ }^{\alpha \Delta}$-deficient mice. Spontaneous firing rates were recorded during in vitro opioid withdrawal (see Materials and methods) in a total of 229 LC cells (on average, $>5$ cells/slice) from mice chronically treated with morphine or saline. After chronic saline treatment, firing rate values of LC neurons were within the same range as those reported in rat brain slices (Kogan et al, 1992). Moreover, in these saline-treated animals, no difference in the LC cell firing rate was found in the $\mathrm{Creb}^{\alpha \Delta}$ groups, comparing wild-type $(0.79 \pm 0.04 \mathrm{~Hz}, n=5)$ and mutant $(0.86 \pm 0.06 \mathrm{~Hz}, n=4)$ mice nor in the Creb $1^{\text {NesCre }}$ groups, comparing wild-type $(0.80 \pm 0.05 \mathrm{~Hz}, n=5)$ and mutant $(0.72 \pm 0.10 \mathrm{~Hz}, n=6)$ mice (Figure 9). After chronic morphine treatment in wild-type mice, firing rates of LC cells were elevated by $87 \%(n=5, p<0.001)$ in the $C r e b 1^{\alpha \Delta}$ control group and by $63 \%$ in $\mathrm{Creb}^{\mathrm{NesCre}}$ control group $(n=6, p<0.05)$, with respect to saline-treated groups (Figure 9). This increase was quantitatively similar to the change reported previously in slices from morphinedependent rats (Lane-Ladd et al, 1997). However, in both $\mathrm{Creb}_{1}^{\alpha \Delta}$ and $\mathrm{Creb} 1^{\mathrm{NesCre}}$ mutant mice, firing activities of LC neurons were not increased after chronic morphine treatment ( $n=6$ and 7, respectively; $p<0.001$ and $<0.05$,

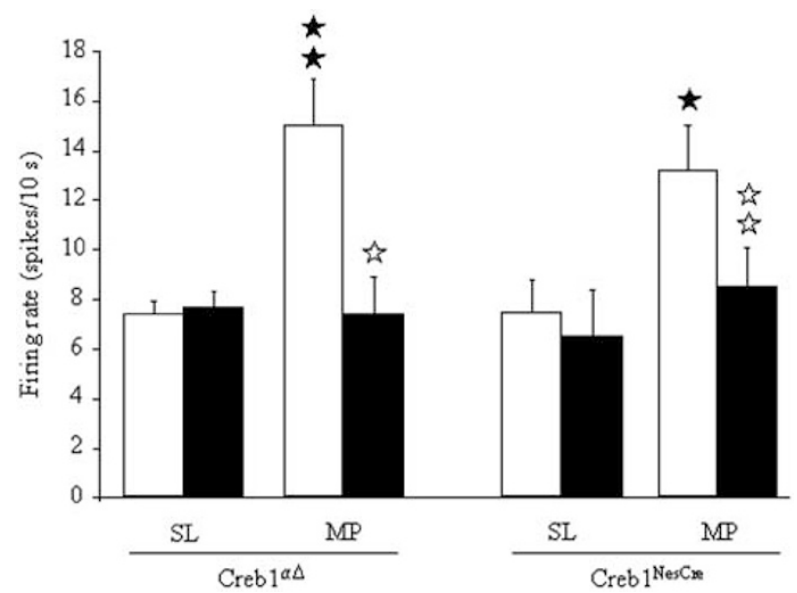

Figure 9 Blockade of morphine withdrawal-induced hyperactivity of LC cells in Creb $\left.\right|^{\text {NesCre }}$ and Creb $\left.\right|^{\alpha \Delta}$ mice. Firing rates of LC neurons were obtained during opiate withdrawal in brain slices from wild-type (white bars) and Crebl mutant (black bars) mice. SL-saline treatment; $M P$ - morphine treatment. Data are represented as mean $\pm S E M$ from four to seven animals. One black star, $p<0.05$; two black stars, $p<0.0$ I compared with corresponding saline group; one white star, $p<0.05$; two white stars $p<0.01$ compared with corresponding wild-type group receiving the same treatment (Newman-Keuls test).

respectively) (Figure 9). Thus, a significant prevention of the withdrawal-induced hyperactivity of LC cells from morphine-dependent animals was observed in both mutant mice groups $(p<0.001$ and $<0.05$, respectively). The possibility of residual morphine present in the slice from dependent animals was explored by the administration of naloxone immediately after the cell sampling. As expected (Kogan et al, 1992), naloxone $(1 \mu \mathrm{M})$ failed to change the firing rate of LC cells in either group (data not shown), confirming the existence of spontaneous morphine withdrawal.

\section{DISCUSSION}

Changes in a transcription factor can produce diverse functional consequences, including several physiopathological alterations, such as modifications in emotional-like behavior and in the development of drug dependence. Defining the multiple molecular changes occurring during the development of these phenomena in vivo, has, in part, relied on the use of genetically modified mice. The interpretations developed from the use of mutant mice have relied on the robustness of the behavioral phenotype, as well as the complexity of the downstream molecular/ cellular changes in these modified mice. A complicating factor in the use of classical germline 'knockout' approaches in such analyses is the involvement of pleiotropic changes/ effects, which may confound the interesting phenotype, in this case behavioral or physiological perturbations without and following drug administration.

We previously showed that hypomorphic $\mathrm{Creb}^{\alpha \Delta}$ mice displayed attenuation of naloxone-precipitated morphine withdrawal syndrome (Maldonado et al, 1996). Here, we show that this phenotype is indeed robust as it is seen in a more genetically defined C57BL/6 background. Considering that $\mathrm{Creb}^{\alpha \Delta}$ mice have an increase in CREB $\beta$ (Blendy et al, 
1996b) and the lethality of complete CREB loss (Hummler et al, 1994), the interpretations addressing complete CREB loss could only be answered using conditional Creb1 mutant mice.

By generating nervous system-specific Creb1 mutant mice (Creb1 ${ }^{\text {NesCre }}$ mice), we were now able to obtain viable mice lacking all CREB isoforms in the nervous system. Examination of $\mathrm{Crebl}^{\mathrm{NesCre}}$ mouse brains showed that CREB immunoreactivity was lost in almost all brain regions, including the nucleus accumbens (Figure 1f). The only area that retained significant CREB expression was the LC (Figure 1d). CREB-TH double labeling showed that almost all TH-positive cells of the LC were also CREB positive (Figure 2a). Creb1 ${ }^{\alpha \Delta}$ hypomorphic mice (this paper) and CREB antisense-treated rats (Lane-Ladd et al, 1997) have a reduction of CREB expression in the LC, which correlates nicely with the attenuation in withdrawal-induced neuron hyperactivity. This is not the case for the LC from Creb $1^{\text {NesCre }}$ mice, in which CREB expression is not reduced but CREM levels are elevated. However, CREB protein in the LC from Creb $1^{\text {NesCre }}$ mice may not be fully functional since CREM upregulation points to the presence of a decreased negative feedback and thus a lower level of functional CREB.

As previously stated, this study relied on the use of the $C r e b 1^{\text {NesCre }}$ mice, which were $70-80 \%$ in size and weight compared with littermate controls due to reduced $\mathrm{GH}$ and IGF-I levels (not shown). A positive correlation between IGF-I and muscle strength has been reported, and IGF-I administration ameliorates muscle weakness syndromes in mice (Kaspar et al, 2003). However, a possible modification of muscle strength does not seem to be important for the behavioral changes observed in the $\mathrm{Creb} 1^{\text {NesCre }}$ mice since other behavioral responses directly related to muscle force, such as jumping were not modified in these animals in the hot-plate test and during the evaluation of morphine withdrawal. On the other hand, the pituitary defective Ames dwarf mice, which present a GH deficiency showed a decreased spontaneous locomotion, but the responses in the elevated plus maze were not modified in these mice (Kinney et al, 2001), unlike the Creb1 ${ }^{\mathrm{NesCre}}$ mice.

Our findings clearly indicate that the CREB transcription factor is implicated in emotional-like behavior, since the absence of CREB increased in anxiety-like behavior in the different behavioral paradigms evaluated, including elevated zero maze, elevated plus maze, black and white box, and open field. Significant reduction in locomotor activity in $C r e b 1^{\text {NesCre }}$ mice was only seen under stressful conditions (in the open-field test, black and white test). The increase in the anxiety level does not seem to be due to a decrease in locomotion, because the decrease in spontaneous locomotion was only observed in $C r e b 1^{\alpha \Delta}$ mice, and these mice elicited anxiogenic-like responses even when the locomotor activity was not decreased after habituation (data not

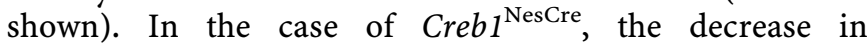
locomotor response was only observed under the stressful situation, and the anxiety-like responses were consistently observed through all the behavior models investigated. In this sense, the CREB-related transcription factor CREM has also been implicated in the control of emotional-like behavior as $\mathrm{Crem}^{-1-}$ mice exhibit a rather complex alteration in emotional and locomotor behaviors. Indeed, $\mathrm{Crem}^{-/-}$mice show an increase in spontaneous locomotor activity and reduced anxiety-like behavior (Maldonado et al, 1999). These results underscore the complexity of the genetics and transcription factor balance underlying such behaviors, as CREB-deficient mice have increased the levels of both activator and repressor CREM isoforms and given that lack of CREM leads to an apparently contrasting phenotype (Maldonado et al, 1999). In agreement with our results, mice with $\mathrm{Creb}^{\alpha \Delta}$ mutation on a defined B6/129F1 background have also been reported to show anxiogeniclike responses in the elevated plus maze (Graves et al, 2002). Furthermore, a decrease in CREB function in the central amygdala has been described to be a common factor in anxiety and alcohol abuse disorders (Pandey et al, 2003). As reduced phosphorylation of CREB is associated with decreased expression of NPY, it could be possible that CREB regulates both anxiety and alcohol abuse behaviors through the NPY system (Pandey, 2003). Other studies have reported that aversive stimuli such as stress activate CREmediated transcription in the nucleus accumbens shell (Barrot et al, 2002). We show here that CREB activity presumably in limbic areas is necessary to provide an appropriate response to stress, since the lack of neural CREB induces an anxiogenic-like state.

To further investigate the involvement of CREB in addictive behaviors, we used conditioned place preference to examine the possible alteration in the rewarding properties of morphine, cocaine, and food in Creb1 mice. Although, loss or deficiencies of CREB in the brain led to clear alterations in withdrawal, we saw no significant changes in morphine rewarding responses, revealing a clear dissociation between physical dependence and motivational responses induced by drug of abuse. Indeed, our results indicate that CREB deficiency in the $C r e b 1^{\alpha \Delta}$ mice, and the loss of CREB in brains of Creb $1^{\text {NesCre }}$ mice, did not modify the rewarding properties elicit by morphine. In addition, we have also investigated in $\mathrm{Creb}^{\alpha \Delta}$ the rewarding responses induced by cocaine, another drug of abuse, and food, a natural reward in the same conditioned place-preference paradigm. The results obtained with these stimuli were similar to those reported with morphine. Thus, mutant mice presented an intact capability to reveal cocaine and food reward in this behavioral model. Contradictory results have been previously reported concerning this topic. Thus, overexpression of CREB in rat nucleus accumbens decreases the rewarding effect of cocaine, whereas a herpes simplex virus vector expressing dominant-negative CREB injected into the same structure led to enhanced cocaine rewarding effects significantly (Carlezon et al, 1998). In contrast, Walters and Blendy (2001) recently showed that $\operatorname{Creb}^{\alpha \Delta}$ mice (F1 hybrid 129SvEv $\times$ C57BL/6) did not exhibit morphine-conditioned place preference but, in agreement with our results, mutant mice did exhibit cocaine-conditioned place preference. The $C r e b 1^{\alpha \Delta}$ mice used in this study differed from those described by Walters and Blendy (2001), only in the genetic background: mice were backcrossed for seven generations in $\mathrm{C} 57 \mathrm{BL} / 6$ in this study, and the rewarding properties of morphine and cocaine were maintained in the both mutant lines of Creb1. One possibility to explain our results is since CREM is upregulated in all neurons devoid of, or deficient in CREB, in $\mathrm{Creb1}^{\mathrm{NesCre}}$ and $\mathrm{Creb}^{\alpha \Delta}$ mice, respectively, CREM may be able to compensate for CREB in the case of motivational 
responses but not in withdrawal-associated responses, possibly revealing subtle differences between CREB and CREM activity. We have recently shown that CREM can compensate for the absence of CREB with respect to neuronal survival (Mantamadiotis et al, 2002). Finally, changes in the emotional state have been reported to influence the rewarding properties of different drugs. Thus, elevated levels of stress are able to produce an anhedonic state and to impair the ability to feel rewarded (Willner, 1990; Valverde et al, 1997). In this study, Creb1 mice exhibited anxiogenic-like responses in all the models evaluated, but this increase in the anxiety levels does not seem to influence the rewarding properties of the different compounds evaluated here, since a similar rewarding response was observed in both wild-type and mutant mice.

The attenuation of morphine withdrawal behavior in $C r e b 1^{\alpha \Delta}$ mice is similar to the attenuation in the Creb $1^{\text {NesCre }}$ mice, which lack all isoforms of CREB restricted to the nervous system. Moreover, we showed that the attenuation of withdrawal response is associated with a reduction in the LC firing rates. However, there appears to be a dissociation between morphine physical dependence and motivational responses. CREB has been shown to be increased in the LC during morphine dependence (Guitart et al, 1992), and to play a crucial role in the behavioral manifestations of morphine withdrawal (Maldonado et al, 1996; Lane-Ladd et al, 1997). Indeed, a reduction in the somatic signs of morphine withdrawal was observed in mice deficient in $\alpha$ and $\Delta$ isoforms of CREB in a mixed 129SvOla $\times$ C57BL/6 genetic background (Maldonado et al, 1996). This decrease in morphine abstinence was confirmed for the same mutation in this study, with mice in a more homogeneous genetic background achieved by successive crossing in $\mathrm{C} 57 \mathrm{BL} / 6$ mice for seven generations. In these $\mathrm{C} 57 \mathrm{BL} / 6$ backcrossed mice, we have now demonstrated that the loss of CREB $\alpha$ and $\Delta$ isoforms completely prevented the hyperactivity of LC neurons from slice preparations normally induced by morphine withdrawal in wild-type mice. Both $C r e b 1^{\text {NesCre }}$ and $C r e b 1^{\alpha \Delta}$ mice exhibited attenuated morphine withdrawal syndrome and reduced LC neuron firing rates, strengthening and supporting the notion that the phenotype observed in Creb1 $1^{\alpha \Delta}$ mice in this and a previous study (Maldonado et al, 1996) was primarily a consequence of CREB loss in the nervous system. Furthermore, it also implies that CREB $\alpha$ and $\Delta$ are the major CREB isoforms involved in the expression of morphine withdrawal syndrome. CREB transcription factor activity is regulated by phosphorylation. The phosphorylation state of CREB is modified by repeated exposure to a drug of abuse, which would lead to altered expression of their target genes. Several additional transcription factors, such as c-Fos, are induced among these target genes (Nestler, 2001). In this sense, different drugs of abuse have been shown to induce $\Delta$ fosB in discrete areas of the brain. Interestingly, $\Delta$ fosB persists in the brain for a long time period and has been related to changes in drug rewarding effects after repeated administration (Kelz and Nestler, 2000).

There were differences in both the altered spectrum of behaviors and strength of attenuation of withdrawal behaviors between $C r e b 1^{\text {NesCre }}$ and $C r e b 1^{\alpha \Delta}$ mice, with
$C r e b 1^{\alpha \Delta}$ mice exhibiting a broader and stronger attenuation compared with Creb1 $1^{\text {NesCre }}$ mice. The differences in withdrawal behavior may be due to several factors. Creb $1^{\text {NesCre }}$ mice lack CREB in all brain regions except a subset of LC neurons, while $C r e b 1^{\alpha \Delta}$ mice lack CREB $\alpha$ and $\Delta$ throughout, suggesting that certain manifestations of the withdrawal syndrome may also be dependent on nonneuronal influences. Differences between $\mathrm{Creb}_{1}{ }^{\mathrm{NesCre}}$ and $\mathrm{Creb1}^{\alpha \Delta}$ genetic backgrounds could be important, although we do not favor this possibility, since we have now reproduced the same altered spectrum of withdrawal behavioral signs in $\mathrm{Creb1}^{\alpha \Delta}$ mice in two different genetic backgrounds: a C57BL/ $6 \times 129$ SvOla mix (Maldonado et al, 1996) and a relatively homogeneous C57BL/6 background (this study). A further difference could be due to differences in the neuroanatomical CREB expression profile, where CREB is present in the LC in $C r e b 1^{\text {NesCre }}$ mice, while in the germline mutant $\operatorname{Creb1}^{\alpha \Delta}$ mice, CREB $\alpha$ and $\Delta$ are uniformly absent.

Controversial data have been previously reported on the role played by the $\mathrm{LC}$ in the expression of morphine abstinence. The firing rate of LC neurons was strongly increased during spontaneous and antagonist-precipitated morphine withdrawal, which seems to contribute to the behavioral expression of the somatic signs of abstinence (Rasmussen and Aghajanian, 1989; Rasmussen et al, 1990). Moreover, the LC was the most sensitive brain structure to precipitate the somatic signs of morphine withdrawal by microinjection of opioid antagonists (Maldonado et al, 1992a,b), and its electrolytic lesion strongly inhibited opioid abstinence (Maldonado and Koob, 1993). Other studies, however, found that morphine-treated rats failed to exhibit opioid withdrawal hyperactivity in the LC (Bell and Grant, 1998) or that lesions of the noradrenergic brain pathways emanating from the LC failed to attenuate the somatic signs of opioid withdrawal (Britton et al, 1984; Caille et al, 1999; Delfs et al, 2002). The latter studies, which have relied on chemically induced lesions of the LC, differ from our findings, which provide important support for the relevance of the firing rate of LC neurons in the expression of morphine withdrawal. However, in the present study, the fact that CREB expression remains unchanged in the LC of $C r e b 1^{\text {NesCre }}$ mutant mice implies that CREB in other areas of the brain must also be required for the development of morphine-induced intrinsic changes in the LC as measured by single-unit extracellular recordings. Owing to the loss of CREB in all brain regions except the LC in Creb1 ${ }^{\text {NesCre }}$ mice, the role of CREB in LC function appears to be bipartite, playing a role in intrinsic LC function and by altering the function of afferents to the LC. Moreover, this finding suggests that neuronal adaptations within the LC, resulting from CREB-induced extrinsic mechanisms are stable ex vivo.

In conclusion, using both germline hypomorphic $C r e b 1^{\alpha \Delta}$ mice and nervous system-specific conditional Creb $1^{\text {NesCre }}$ mice, we have demonstrated that the presence of CREB is crucial for the maintenance of the emotional behavior and have been able to attenuate morphine withdrawal without changes in the rewarding properties of drugs (cocaine and morphine) and natural stimuli (food). This response is attributed to CREB function. Our understanding of the molecular mechanisms involved in the control of emotional behavior and the development of drug addiction, where 
CREB plays a pivotal role, contributes to the knowledge of how to pharmacologically intervene in the biochemical pathways involved in these processes.

\section{ACKNOWLEDGEMENTS}

We thank Stephanie Ridder for tireless help with genotyping and mouse work, and Annette Klewe-Nebenius for assistance with mouse handling. We also thank Drs Erich Greiner, Thomas Lemberger, Christiane Otto, and François Tronche for helpful discussions. This work was funded by specific grants from European Community Biomed-2 program, Contract No. BMH4-CT98-2267, UPV026.327G13/98, SAF99-0046, E-315.BIO4-CT98-0297, DFG-SFB 488, 'Plan Nacional sobre Drogas', Generalitat de Catalunya (Research Distinction and 20025GR00193), and Ministry of Science and Technology (SAF 2001-0745).

\section{REFERENCES}

Barrot M, Olivier JDA, Perrotti LI, DiLeone RJ, Berton O, Eisch AJ et al (2002). CREB activity in the nucleus accumbens shell controls gating of behavioral responses to emotional stimuli. Proc Natl Acad Sci USA 99: 11435-11440.

Bell JA, Grant SJ (1998). Locus coeruleus neurons from morphinetreated rats do not show opiate-withdrawal hyperactivity in vitro. Brain Res 788: 237-244.

Berke JD, Hyman SE (2000). Addiction, dopamine, and the molecular mechanisms of memory. Neuron 25: 515-532.

Blendy JA, Kaestner KH, Schmid W, Gass P, Schutz G (1996b). Targeting of the CREB gene leads to up-regulation of a novel CREB mRNA isoform. EMBO J 15: 1098-1106.

Blendy JA, Kaestner KH, Weinbauer GF, Nieschlag E, Schutz G (1996a). Severe impairment of spermatogenesis in mice lacking the CREM gene. Nature 380: 162-165.

Bourtchuladze R, Frenguelli B, Blendy J, Cioffi D, Schutz G, Silva AJ (2002). Deficient long-term memory in mice with a targeted mutation of the cAMP-responsive element-binding protein. Cell 79: $59-68$.

Britton KT, Svensson T, Schwartz J, Bloom FE, Koob GF (1984). Dorsal noradrenergic bundle lesions fail to alter opiate withdrawal or suppression of opiate withdrawal by clonidine. Life Sci 34: 133-139.

Caille S, Espejo EF, Reneric JP, Cador M, Koob GF, Stinus L (1999). Total neurochemical lesion of noradrenergic neurons of the locus ceruleus does not alter either naloxone-precipitated or spontaneous opiate withdrawal nor does it influence ability of clonidine to reverse opiate withdrawal. J Pharmacol Exp Ther 290: 881-892.

Carlezon Jr WA, Thome J, Olson VG, Lane-Ladd SB, Brodkin ES, Hiroi $\mathrm{N}$ et al (1998). Regulation of cocaine reward by CREB. Science 282: 2272-2275.

Delfs JM, Zhu Y, Druhan JP, Aston-Jones G (2002). Noradrenaline in the ventral forebrain is critical for opiate withdrawal-induced aversion. Nature 403: 430-434.

Di Chiara G, North RA (1992). Neurobiology of opiate abuse. Trends Pharmacol Sci 13: 185-193.

Graves L, Dalvi A, Lucki I, Blendy JA, Abel T (2002). Behavioral analysis of $\mathrm{CREB} \alpha \Delta$ mutation on a B6/129 F1 hybrid background. Hippocampus 12: 18-26.

Guitart X, Thompson MA, Mirante CK, Greenberg ME, Nestler EJ (1992). Regulation of cyclic AMP response element-binding protein (CREB) phosphorylation by acute and chronic morphine in the rat locus coeruleus. J Neurochem 58: 1168-1171.

Hummler E, Cole TJ, Blendy JA, Ganss R, Aguzzi A, Schmid W et al (1994). Targeted mutation of the CREB gene: compensation within the CREB/ATF family of transcription factors. Proc Natl Acad Sci USA 91: 5647-5651.

Josselyn SA, Kida S, de Ortiz P, Silva AJ (2002). CREB, plasticity and memory. In: Kaczmarek L, Robertson HA (eds) Handbook of Chemical Neuroanatomy: Immediate Early Genes and Inducible Transcription Factors in Mapping of the Central Nervous System Function and Dysfunction. Elsevier: Amsterdam.

Kaspar BK, Lladó J, Sherkat N, Rothstein JD, Gage FH (2003). Retrograde viral delivery of IGF-1 prolongs survival in a mouse ALS model. Science 301: 839-842.

Kelz MB, Nestler EJ (2000). $\Delta$ fosB: a molecular switch underlying long-term neural plasticity. Curr Opin Neurol 13: 715-720.

Kinney BA, Meliska CJ, Steger RW, Bartke A (2001). Evidence that Ames dwarf mice age differently from their normal siblings in behavioral and learning and memory parameters. Horm Behav 39: 277-284.

Kogan JH, Nestler EJ, Aghajanian GK (1992). Elevated basal firing rates and enhanced responses to 8-Br-cAMP in locus coeruleus neurons in brain slices from opiate-dependent rats. Eur J Pharmacol 211: 47-53.

König M, Zimmer AM, Steiner H, Holmes PV, Crawley JN, Brownstein MJ et al (1996). Pain responses, anxiety and aggression in mice deficient in pre-proenkephalin. Nature 383 : 535-538.

Koob GF, Le Moal M (1997). Drug abuse: hedonic homeostatic dysregulation. Science 278: 52-58.

Koob GF, Sanna PP, Bloom FE (1998). Neuroscience of addiction. Neuron 21: 467-476.

Lane-Ladd SB, Pineda J, Boundy VA, Pfeuffer T, Krupinski J, Aghajanian GK et al (1997). CREB (cAMP response elementbinding protein) in the locus coeruleus: biochemical, physiological, and behavioral evidence for a role in opiate dependence. J Neurosci 17: 7890-7901.

Lonze BE, Riccio A, Cohen S, Ginty DD (2002). Apoptosis, axonal growth defects, and degeneration of peripheral neurons in mice lacking CREB. Neuron 34: 371-385.

Maldonado R, Blendy JA, Tzavara E, Gass P, Roques BP, Hanoune J et al (1996). Reduction of morphine abstinence in mice with a mutation in the gene encoding CREB. Science 273: 657-659.

Maldonado R, Koob GF (1993). Destruction of the locus coeruleus decreases physical signs of opiate withdrawal. Brain Res 605: 128-138.

Maldonado R, Negus S, Koob GF (1992a). Precipitation of morphine withdrawal syndrome in rats by administration of mu-, delta- and kappa-selective opioid antagonists. Neuropharmacology 31: 1231-1241.

Maldonado R, Saiardi A, Valverde O, Samad TA, Roques BP, Borrelli E (1997). Absence of opiate rewarding effects in mice lacking dopamine D2 receptors. Nature 388: 586-589.

Maldonado R, Smadja C, Mazzucchelli C, Sassone-Corsi P, Mazucchelli C (1999). Altered emotional and locomotor responses in mice deficient in the transcription factor CREM. Proc Natl Acad Sci USA 96: 14094-14099.

Maldonado R, Stinus L, Gold LH, Koob GF (1992b). Role of different brain structures in the expression of the physical morphine withdrawal syndrome. J Pharmacol Exp Ther 261: 669-677.

Mantamadiotis T, Lemberger T, Bleckmann SC, Kern H, Kretz O, Villalba AM et al (2002). Disruption of CREB function in brain leads to neurodegeneration. Nat Genet 31: 47-54.

Mantamadiotis T, Taraviras S, Tronche F, Schutz G (1998). PCRbased strategy for genotyping mice and ES cells harboring loxP sites. Biotechniques 25: 968-970; 972.

Mayr B, Montminy M (2001). Transcriptional regulation by the phosphorylation-dependent factor CREB. Nat Rev Mol Cell Biol 2: 599-609.

Nestler EJ (1997). Molecular mechanisms of opiate and cocaine addiction. Curr Opin Neurobiol 7: 713-719. 
Nestler EJ (2001). Molecular basis of long-term plasticity underlying addiction. Nat Rev Neurosci 2: 119-128.

Nestler EJ, Aghajanian GK (1997). Molecular and cellular basis of addiction. Science 278: 58-63.

Nestler EJ, Barrot M, Dileone SJ, Eisch AJ, Gold SJ, Monteggia LM (2002). Neurobiology of depression. Neuron 34: 13-25.

Nestler EJ, Hope BT, Widnell KL (1993). Drug addiction: a model for the molecular basis of neural plasticity. Neuron 11: 995-1006.

Nibuya M, Nestler EJ, Duman RS (1996). Chronic antidepressant administration increases the expression of cAMP response element binding protein (CREB) in rat hippocampus. J Neurosci 16: $2365-2372$.

NIH (1985). Guide for Care and Use of Laboratory Animals, no. 82-85.

Pandey SC (2003). Anxiety and alcohol abuse disorders: a common role for CREB and its target, the neuropeptide Y gene. Trends Pharmacol Sci 24: 456-460.

Pandey SC, Roy A, Zhang H (2003). The decreased phosphorylation of cyclic adenosine monophosphate (cAMP) response element binding (CREB) protein in the central amygdala acts as a molecular substrate for anxiety related to ethanol withdrawal in rats. Alcoholism: Clin Exp Res 27: 396-409.

Rasmussen K, Aghajanian GK (1989). Withdrawal-induced activation of locus coeruleus neurons in opiate-dependent rats: attenuation by lesions of the nucleus paragigantocellularis. Brain Res 505: 346-350.
Rasmussen K, Beitner Johnson DB, Krystal JH, Aghajanian GK, Nestler EJ (1990). Opiate withdrawal and the rat locus coeruleus: behavioral, electrophysiological, and biochemical correlates. J Neurosci 10: 2308-2317.

Rudolph D, Tafuri A, Gass P, Hammerling GJ, Arnold B, Schutz G (1998). Impaired fetal T cell development and perinatal lethality in mice lacking the cAMP response element binding protein. Proc Natl Acad Sci USA 95: 4481-4486.

Thome J, Sakai N, Shin K, Steffen C, Zhang YJ, Impey S et al (2000). cAMP response element-mediated gene transcription is upregulated by chronic antidepressant treatment. J Neurosci 20: 2404-2412.

Tronche F, Kellendonk C, Kretz O, Gass P, Anlag K, Orban PC et al (1999). Disruption of the glucocorticoid receptor gene in the nervous system results in reduced anxiety. Nat Genet 23: 99-103. Valverde O, Smadja C, Roques BP, Maldonado R (1997). The attenuation of morphine-conditioned place preference following chronic mild stress is reversed by a CCKB receptor antagonist. Psychopharmacology 131: 79-85.

Walters CL, Blendy JA (2001). Different requirements for cAMP response element binding protein in positive and negative reinforcing properties of drugs of abuse. J Neurosci 21: 94389444.

Willner P (1990). Animal models of depression: an overview. Pharmacol Ther 45: 425-455. 